\title{
TKJ Laboratory Inventory Monitoring System Using Web-based AHP (Analytical Hierarchy Process) Method at SMK Negeri 1 Doko
}

\section{Sistem Monitoring Inventaris Laboratorium TKJ Menggunakan Metode AHP (Analytical Hierarchy Process) Berbasis Web di SMK Negeri 1 Doko}

\author{
Budi Prasetyo ${ }^{1}$, Dimas Fanny Hebrasianto Permadi ${ }^{2}$ \\ [ budi86jk@gmail.com ${ }^{1}$, dime.ask@gmail.com ${ }^{2}$ ]
}

Program Studi Teknik Informatika, Fakultas Teknologi Informasi, Universitas Islam Balitar Blitar

\begin{abstract}
Reporting and collecting data on inventory tools using the old method does not rule out the possibility of data reporting errors and determining priorities for procurement of laboratory inventory at SMK Negeri 1 Doko. The development of increasingly advanced technology requires computerized inventory data collection, which is expected to reduce paper use, so that checking inventory conditions can be easy and efficient. To make it easier to determine the procurement of inventory, a system is needed that can make it easier to determine the priority of inventory procurement and is expected to help problems in MK Negeri 1 Doko. Therefore, research will be carried out with the aim of making it easier to monitor and determine priorities for laboratory inventory procurement. This research is a development research using the waterfall method using the AHP algorithm for system development. The results showed that the results obtained from testing the AHP calculation manually or using the application obtained that there were several values that had a difference of 0.000001 the consistency ratio showed less than 10\%. It could be concluded that the AHP calculation was still acceptable. BlackBox testing and beta testing the user satisfaction level of $88.25 \%$ indicates that the monitoring application system built is acceptable and can run according to its function.
\end{abstract}

Keyword : Inventory Monitoring System, Analytical Hierarchy Process (AHP), Waterfall, Black Box testing.

Abtrak-Pelaporan dan pendataan alat inventaris yang menggunkan cara lama tidak menutup kemungkinan terjadi kesalahan pelaporan data dan menentukan prioritas pengadaan inventaris laboratorium di SMK Negeri 1 Doko. Perkembangan teknologi yang semakin maju mengharuskan pendataan inventaris terkomputerisasi, diharapkan dapat mengurangi penggunaan kertas, sehingga dalam hal pengecekan kondisi inventaris dapat menjadi mudah dan efisien. Untuk memudahkan dalam menentukkan pengadaan inventaris dibutuhkan sebuah sistem yang dapat memudahkan dalam hal menentukan prioritas pengadaan inventaris dan diharapkan dapat membantu masalah-maslah di MK Negeri 1 Doko. Oleh karena itu akan dilakukan penelitian dengan tujuan untuk memudahkan dalam memonitoring dan menentukan prioritas pengadaan inventaris laboratorium. Penelitian yang dilakukan merupakan penelitian pengembangan dengan metode waterfall menggunakan algoritma AHP untuk pengembangan sistemnya. Hasil penelitian menunjukkan bahwa diperoleh hasil dari pengujian perhitungan AHP secara manual maupun menggunakan aplikasi diperoleh ada bebrapa nilai yang mempunyai selisih 0,000001 rasio konsistensi menunjukkan kurang dari 10\% dapat disimpulkan bahwa perhitungan AHP masih bisa diterima. pengujian blackbox dan pengujian beta tingkat kepuasan user sebesar $88,25 \%$ menunjukan bahwa sistem aplikasi monitoring yang dibangun sudah dapat diterima dan sudah dapat berjalan sesuah dengan fungsinya.

Kata kunci : Sistem Monitoring Inventaris, Analytical Hierarchy Process (AHP), Waterfall, Black Box testing.

\section{PENDAHULUAN}

Penyampaian laporan dan pendataan alat inventaris yang menggunakan cara lama dengan menggunakan media kertas dan mengandalkan catatan sehingga tidak menutup kemungkinan sering terjadi kesalahan dalam pelaporan data. Perkembangan teknologi yang semakin maju mengharuskan pendataan alat iventaris terkomputerisasi dapat mengurangi penggunan kertas, sehingga dalam hal pengecekan kondisi iventaris dapat menjadi mudah, efisien dan tepat.

\section{Inventaris}

Aset tetap atau inventaris adalah barang siap pakai atau dengan dibangun terlebih dahulu, yang digunakan dalam kegiatan operasional, tidak dimaksudkan untuk dijual dan mempunyai manfaat lebih dari satu tahun, seperti tanah, gedung, kantor, kendaraan dan peralatan[1]. 


\section{Penentuan Inventaris menggunakan metode AHP}

Analytical Hierarchy Process adalah salah satu metode untuk membantu menentukan prioritas dari berbagai pilihan menggunakan berbagai kriteria[2].

Untuk menentukan prioritas pengadaan atau penggantian inventaris yang mempunyai kondisi rusak peneliti menggunakan metode Analytical Hierarchy Process (AHP). Metode Analytical Hierarchy Process (AHP) dipilih karena dapat membantu menyelesaikan persoalan yang kompleks dengan menstruktur suatu hierarki kriteria dangan hasil yang baik, hal ini dilakukan dengan menarik berbagai pertimbangan yang bertujuan mengembangkan bobot atau prioritas.

\section{Pengujian Black Box}

Pengujian Black Boxtesting merupakan sebuah metode untuk menguji sebuah software tanpa harus memperhatikan detail suatu software, dengan cara hanya mengambil output pengujian melalui data uji dan memeriksa fungsional dari perangkat lunak[3].

\section{METODE}

Data yang didapat selama proses penelitian kemudian dianalisis sesuai dengan jenis datanya, yaitu jenis data primer dan jenis data sekunder. Jenis data primer adalah data yang didapatkan langsung dari objek penelitian yang berkaitan dengan penelitian yang dilakukan, dari wawancara dan survei atau pengamatan langsung, yang digunakan sebagai dasar dalam pembuatan aplikasi. Jenis data sekunder yaitu data yang didapat dari hasil studi pustaka yang peneliti ambil dari buku, jurnal, literatur dan media internet yang berhubungan dengan penelitian yang dilakukan. Dan semua data - data tersebut dianalisis agar dapat digunakan untuk penelitian ini.

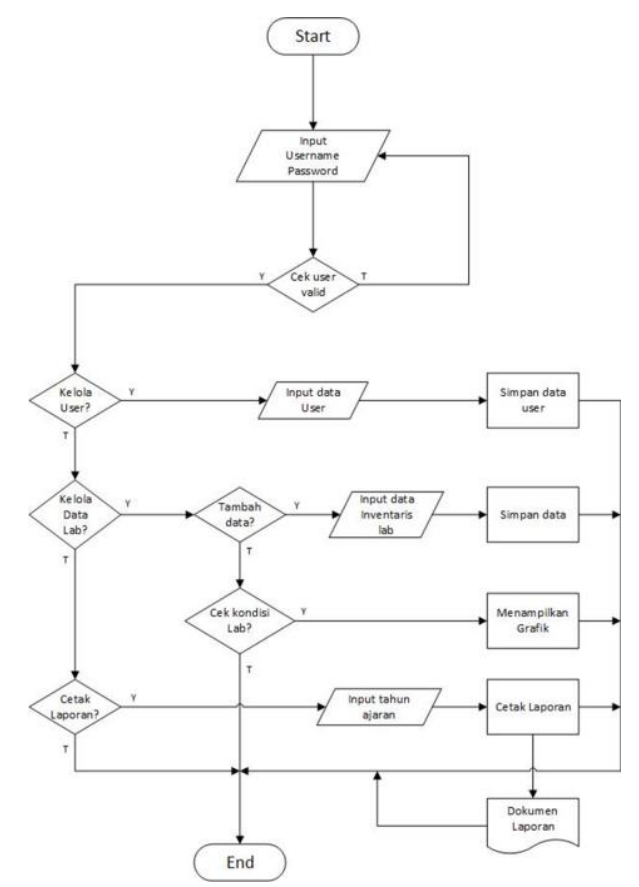

Gambar 1. Flowchart Aplikasi Sistem Monitoring Laboratorium

Gambar 1 dijelaskan proses alur sistem yang akan dibuat pada SMK Negeri 1 Doko, Proses mulai dari Login memasukkan Username dan Password jika proses login berhasil maka akan berlanjut ke menu utama dan jika gagal maka harus memasukkan ulang. Kemudian pengguna diarahkan ke pilihan kelula User, kelola data lab, dan cetak laporan. Pada menu kelola User, pengguna dapat menambah, mengedit dan menghapus data User, dan pada menu kelola data lab pengguna dapat menambah, merubah, dan menghapus data inventaris Lab. Pada menu ceta laporan pengguna diminta untuk mengisikan data tahun ajaran, kemudian juntuk mengakhiri aplikasi pengguna harus menekan tombol Logout. 
Berikut pengujian dan pengambilan data yang akan dilakukan yaitu :

1. Pengujian A merupakan tahap pengujian dan pengambilan data menggunakan pengujian BlackBox yang hasil dari pengujian akan ditampilkan dalambentuk tabel.

2. Pengujian B merupakan tahap pengujian dan pengambilan data menggunakan pengujian Beta untuk menentukan tingkat kepuasan user, yang hasil dari pengujian akan ditampilkan dalam tabel.

\section{HASIL DAN PEMBAHASAN}

Pengujian Black Box dilakukan untuk menguji setiap fungsi dari aplikasi yang dibangun apakah aplikasi sudah berjalan sesuai dengan yang diharapkan. Dari hasil pengujian akan diambil kesimpulan bahwa aplikasi sistem monitoring laboratorium teknik komputer dan jaringan di SMK Negeri 1 Doko yang dibangun sudah berjalan dengan fungsinya.

\section{Penerapan metode AHP}

Pada tahap ini merupakan implementasi metode AHP pada aplikasi monitoring laboratorium Teknik Komputer dan Jaringan. Berikut ini tampilan halaman Data Kriteria aplikasi monitoring laboratorium

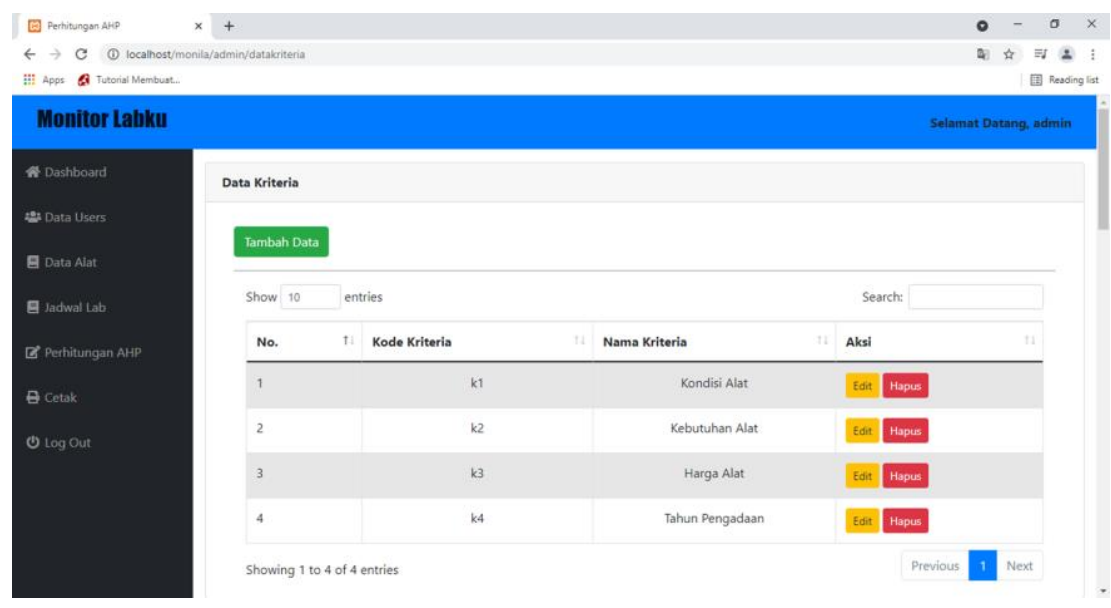

Gambar 2. Kriteria Perhitungan AHP

Gambar 2 menunjukkan halaman data kriteria yang akan digunakan dalam perhitungan AHP, pada tampulan ini user dapat melakukan tambah, edit dan hapus data kriteria. Berikut ini tampilan halaman Data Alternatif aplikasi monitoring laboratorium.

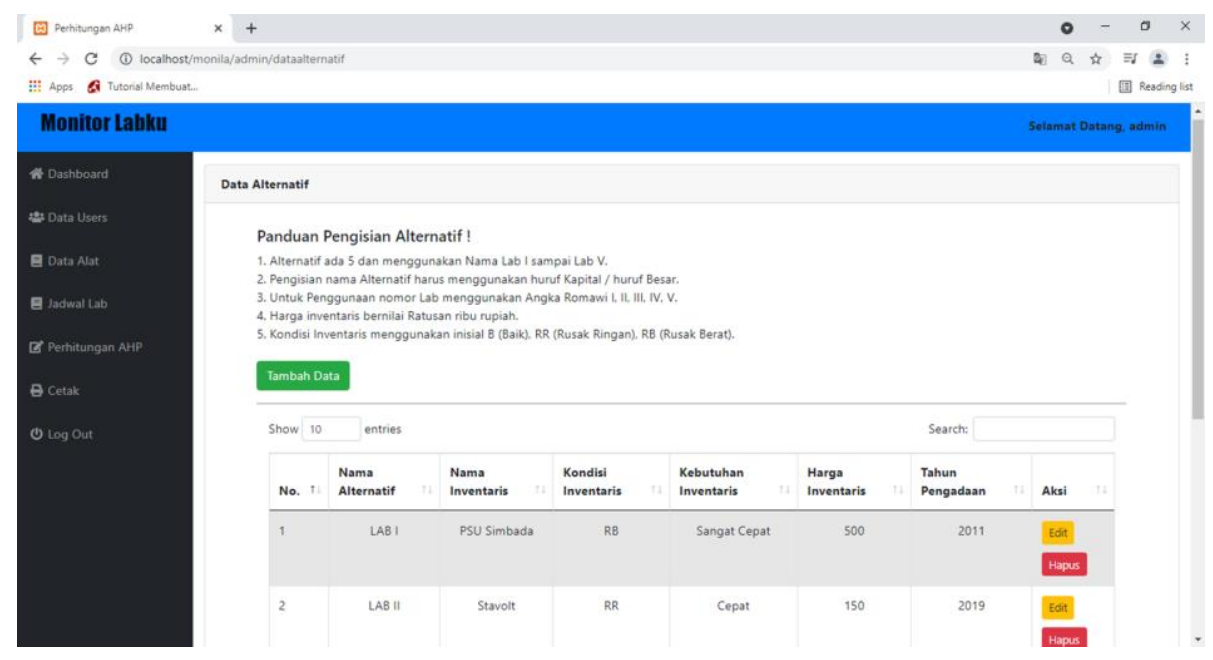

Gambar 3. Alternatif Perhitungan AHP

Gambar 3 yaitu halaman data alternatif, disini user dapat memasukkan alternatif yang akan dihitung dalam proses Analytical Hierarchy Process (AHP) dan terdapat panduan dalam mengisikan data alternatif. Pada bawah tabel data alternatif terdapat penjelasan mengenai index RI, yang digunakan untuk menghitung tingkat 
Procedia of Enginering and Life Science Vol. 2. No. 1 Oktober 2021

Seminar Nasional \& Call Paper Fakultas Sains dan Teknologi (SENASAINS 3rd)

Universitas Muhammadiyah Sidoarjo

konsisten perhitungan atau perbandingan tersebut. Berikut ini tampilan halaman tabel perbandingan kriteria pada metode AHP aplikasi monitoring laboratorium

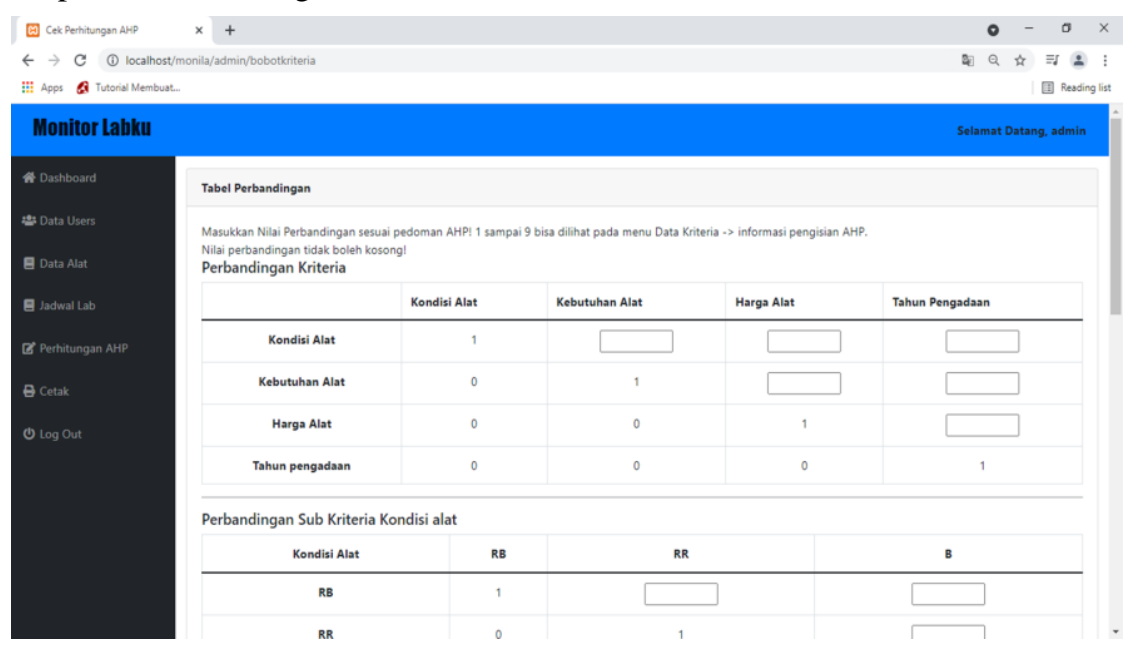

Gambar 4. Perbandingan Kriteria AHP

Gambar 4 menampilkan Proses Perhitungan perbandingan nilai kriteria menggunakan metode AHP, untuk menunjukkan perhitungan itu bernar ditunjukkan pada tabel Lamda Max, CI dan CR yang menampilkan bahwa perhitungan tersebut konsisten sehingga dapat digunakan untuk menghitung hasil perhitungan alternatif. Berikut ini tampilan hasil perhitungan AHP.

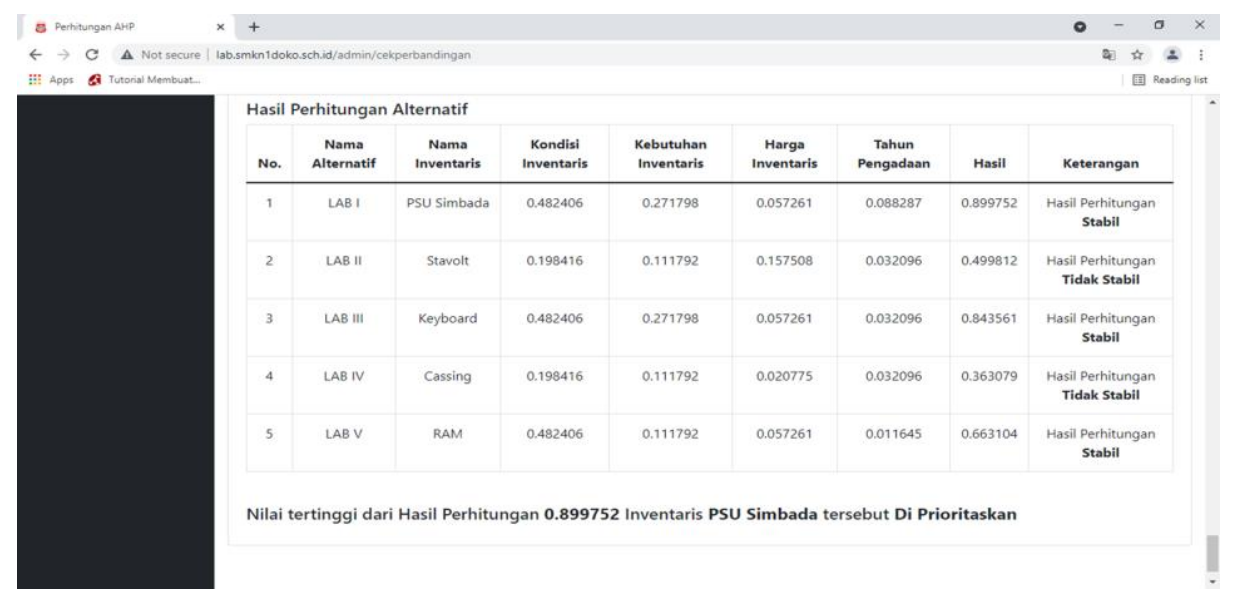

Gambar 5. Hasil Perhitungan AHP

Gambar 5 menunjukkan hasil perhitungan Analytical Hierarchy Process (AHP), hasil prioritas alternatif ditunjukkan dengan nilai tertinggi dari perhitungan yang di tampilkan pada pemberitahuan dibawah tabel perhitungan alternatif. 
Procedia of Enginering and Life Science Vol. 2. No. 1 Oktober 2021

Seminar Nasional \& Call Paper Fakultas Sains dan Teknologi (SENASAINS 3rd)

Universitas Muhammadiyah Sidoarjo

Tabel 1. Perbandingan Perhitungan AHP secara Manual dengan Aplikasi

\begin{tabular}{ccccccccc}
\hline & \multicolumn{4}{c}{ Perhitungan Manual } & & & \multicolumn{3}{c}{ Perhitungan Aplikasi } \\
\hline $\begin{array}{c}\text { Nama } \\
\text { inventaris }\end{array}$ & $\begin{array}{c}\text { Kondisi } \\
\text { Inventaris }\end{array}$ & $\begin{array}{c}\text { Kebutuhan } \\
\text { Inventaris }\end{array}$ & $\begin{array}{c}\text { Harga } \\
\text { Inventaris }\end{array}$ & $\begin{array}{c}\text { Tahun } \\
\text { Pengadaan }\end{array}$ & $\begin{array}{c}\text { Kondisi } \\
\text { Inventar } \\
\text { is }\end{array}$ & $\begin{array}{c}\text { Kebutuh } \\
\text { an } \\
\text { Inventar } \\
\text { is }\end{array}$ & $\begin{array}{c}\text { Hahun } \\
\text { Inventaris } \\
\text { Pengada } \\
\text { an }\end{array}$ \\
\hline $\begin{array}{c}\text { PSU } \\
\text { Simbada }\end{array}$ & 0,482406581 & 0,271797696 & 0,057261286 & 0,088287336 & 0,482406 & 0,271798 & 0,057261 & 0,088287 \\
\hline Stavolt & 0,198416006 & 0,11179162 & 0,157508386 & 0,032096363 & 0,198416 & 0,111792 & 0,157508 & 0,032096 \\
\hline Keyboard & 0,482406581 & 0,271797696 & 0,057261286 & 0,032096363 & 0,482406 & 0,271798 & 0,057261 & 0,032096 \\
\hline Cassing & 0,198416006 & 0,11179162 & 0,020775592 & 0,032096363 & 0,198416 & 0,111792 & 0,020775 & 0,032096 \\
\hline RAM & 0,482406581 & 0,11179162 & 0,057261286 & 0,011645232 & 0,482406 & 0,111792 & 0,057261 & 0,011645 \\
\hline
\end{tabular}

Dari hasil pengujian perhitungan AHP secara manual mupun menggunakan aplikasi dapat disimpulkan bahwa ada bebrapa nilai yang memilik selisih 0,000001 meliputi nilai perhitungan manual $(0,271797696$ dan $0,11179162)$ pada perhitungan aplikasi yang bernilai $(0,271798$ dan 0,111792$)$. Pada perhitungan manual belum di bulatkan menjadi enam angka di belakang koma (nilai asli), sedangkan pada perhitungan aplikasi nilai nya sudah dibulatkan menjadi enam angka di belakang koma. Nilai konsistensi yang diharapkan yaitu mendekati sempurna agar menghasilkan keputusan yang mendekati valid, rasio konsistensi diharapkan kurang dari atau sama dengan $10 \%$. Sehingga dapat disimpulkan bahwa perhitungan manual maupun aplikasi memiliki selisih nilai yang normal dan bisa diterima[1].

Pengujian Black Box

Berikut ini tabel pengujian form login menggunkan pengujian Black Box.

Tabel 2. Pengujian Black Box form login

\begin{tabular}{|c|c|c|c|c|}
\hline Id & Deskripi Pengujian & Hasil yang diharapkan & Hasil yang diperoleh & Kesimpulan \\
\hline A001 & $\begin{array}{l}\text { Mengisi Form login } \\
\text { dengan "admin" dan } \\
\text { Password "123uji" lalu } \\
\text { menekan tombol } \\
\text { "Login" }\end{array}$ & $\begin{array}{l}\text { Sistem menerima dan } \\
\text { menampilakn } \\
\text { pemberitahuan } \\
\text { "Selamat datang } \\
\text { Admin" kemudian } \\
\text { tampil halaman beranda }\end{array}$ & $\begin{array}{l}\text { Sistem menerima dan } \\
\text { menampilakn } \\
\text { pemberitahuan } \\
\text { "Selamat datang } \\
\text { Admin" kemudian } \\
\text { tampil halaman beranda }\end{array}$ & Valid \\
\hline $\mathrm{A} 002$ & $\begin{array}{l}\text { Tidak mengisi } \\
\text { Username dan mengisi } \\
\text { Password "123uji" } \\
\text { kemudian menekan } \\
\text { tombol "Login" }\end{array}$ & $\begin{array}{l}\text { Sistem akan menolak } \\
\text { dan menampilkan pesan } \\
\text { "Field Username harus } \\
\text { diisi" }\end{array}$ & $\begin{array}{l}\text { Sistem akan menolak } \\
\text { dan menampilkan pesan } \\
\text { "Field Username harus } \\
\text { diisi" }\end{array}$ & Valid \\
\hline A003 & $\begin{array}{l}\text { Mengisi Username } \\
\text { dengan "admin" dan } \\
\text { tidak mengisi Password } \\
\text { lalu menekan Tombol } \\
\text { "Login" }\end{array}$ & $\begin{array}{l}\text { Sistem akan menolak } \\
\text { dan menampilkan pesan } \\
\text { "Field Password harus } \\
\text { diisi" }\end{array}$ & $\begin{array}{l}\text { Sistem akan menolak } \\
\text { dan menampilkan pesan } \\
\text { "Field Password harus } \\
\text { diisi" }\end{array}$ & Valid \\
\hline A004 & $\begin{array}{l}\text { Mengisi Username } \\
\text { dengan "Admin" dan } \\
\text { mengisi Password } \\
\text { "123uji" lalu menekan } \\
\text { Tombol "Login" }\end{array}$ & $\begin{array}{l}\text { Sistem akan menolak } \\
\text { dan menampilkan pesan } \\
\text { "Username TIDAK } \\
\text { TERDAFTAR" }\end{array}$ & $\begin{array}{l}\text { Sistem akan menolak } \\
\text { dan menampilkan pesan } \\
\text { "Username TIDAK } \\
\text { TERDAFTAR" }\end{array}$ & Valid \\
\hline
\end{tabular}

Dari Pengujian Black Box testing tersebut yang telah dilakukan oleh 4 responden, dapat disimpulkan bahwa aplikasi yang dibangun sudah dapat berjalan sesuai dengan fungsionalnya dan menghasilkan keluaran yang diharapkan. Akan tetapi tidak menutup kemungkinan pada proses masih terdapat kesalahan. 
Procedia of Enginering and Life Science Vol. 2. No. 1 Oktober 2021

Seminar Nasional \& Call Paper Fakultas Sains dan Teknologi (SENASAINS 3rd)

Universitas Muhammadiyah Sidoarjo

\section{Pengujian Beta}

Berikut ini tabel skala likert yang dugunkan sebagai acuan hasil pengujian Beta.

Tabel 3. Skala Likert

\begin{tabular}{ccc}
\hline Kriteria & Nilai Skala & Persentase \\
\hline Sangat Setuju & 5 & $81 \%-100 \%$ \\
\hline Setuju & 4 & $61 \%-80 \%$ \\
\hline Netral & 3 & $41 \%-60 \%$ \\
\hline Tidak Setuju & 2 & $21 \%-40 \%$ \\
\hline Sangat TidakSetuju & 1 & $1 \%-20 \%$
\end{tabular}

$$
Y=\frac{\sum(N \cdot R)}{\text { Skor Ideal }} \times 100 \%
$$

\section{Keterangan:}

$Y=$ Nilai Persentase

$\sum(\boldsymbol{N} . \boldsymbol{R})=$ Jumlah nilai kategori jawaban dikali dengan frekuensi

$N=$ Nilai dari setiap jawaban

$R=$ Frekuensi

Skor ideal $=$ Nilai tertinggi dikalikan dengan jumlah sampel $(5 \times 30=150)$

Pengujian beta dilakukan dengan memberikan kuisioner kepada 30 responden. Dari pengujian beta yang sudah dilakukan dengan menghitung jumlah skor $1.765 \%$ dibagi dengan 20 sampel peryataan menghasilkan $88.25 \%$. Hasil tersebut diperoleh dari pilihan kategori jawaban kuisioner yang sudah dibagikan dilapangan dapat disimpulkan bahwa sistem monitoring inventaris laboratorium teknik komputer dan jaringan menggunakan metode Analytical Hierarchy Process (AHP) berbasis web di SMK Negeri 1 Doko yang dibangun sudah sesuai dengan tujuan yaitu mudah digunakan, bermanfaat dalam menyampaikan informasi kondisi laboratorium.

\section{KESIMPULAN}

Berdasarkan pembahasan yang telah dipaparkan sebelumnya, maka kesimpulan yang dapat diambil dari penilitian ini adalah sebagai berikut :

1. Perancangan aplikasi sistem monitoring laboratorium menggunkan metode Analytical Hierarchy Process (AHP). Dimulai dengan pengumpulan data informasi yang digunakan untuk pembuatan aplikasi. setelah data terkumpul selanjutnya adalah pembuatan alir data aplikasi dengan membuat Data Flow Diagram (DFD), Entity Relationship Diagram (ERD), Flowchart dan desain paplikasi, untuk database aplikasi menggunakan MySQL, untuk Framework menggunkan CodeIgniter 3. Dalam implementasi aplikasi sudah dapat diakses secara online, admin dan user dapat mengakses aplikasi selama perangkat terkoneksi dengan internet.

2. Untuk menentukan prioritas pengadaan inventaris menggunkan metode Analytical Hierarchy Process (AHP) yaitu dengan membuat kriteria, kemudian membuat alternatif, setelah itu memasukkan nilai perbandingan antara kriteria dengan kriteria dan alternatif dengan alternatif, prioritas didapatkan dari hasil perhitungan perangkingan prioritas nilai akhir menggunakan merode AHP yang menunjukkan nilai tertinggi 0.89975 pada inventaris PSU Simbada dari alternatif inventaris Stavolt, Keyboard, Cassing dan RAM.

3. Pada proses pengujian black box menentukan test case yang akan diujikan dan hasil yang diharapkan dari pengujian black box menunjukkan tingkat akurasi menunjukkan 100\% dapat disimpulkan bahwa aplikasi tersebut sudah berjalan sesuai dengan fungsionalnya. Untuk pengujian beta dilakukan dengan menyebarkan kuesioner yang di dalamnya terdapat lima pernyataan dan jumlah responden sebanyak 30 orang. Hasil pada pengujian beta menunjukkan tingkat kepuasan user sebesar 88,25\%, sehingga dapat disimpulkan bahwa sistem aplikasi monitoring yang dibangun dapat diterima dan sudah dapat berjalan sesuai dengan fungsionalnya.

\section{REFERENSI}

[1] Abdullah, A., \& Pangestika, M. W. (2018). Rancang Bangun Sistem Pendukung Keputusan Dalam Pemilihan Dosen Pembimbing Skripsi Dengan Metode AHP di UM Pontianak. Cybernetics, 2(02), 234. https://doi.org/10.29406/cbn.v2i02.1297 
[2] Sumarsono, E. K. O. (2016). Penerapan metode ahp (analytical hierarchy process) dalam pengendalian persediaan barang pada PT. Sumber rezeki bersama.

[3] Aziz, I. A., Setiawan, B., Khanh, R., Nurdiyansyah, G., \& Yulianti, Y. (2020). Pengujian Black Box pada Aplikasi Sistem Kasir Berbasis Website Menggunakan Teknik Equivalence Partitions. Jurnal Teknologi Sistem Informasi dan Aplikasi, 3(2), 82. https://doi.org/10.32493/jtsi.v3i2.4693

[4] Azza, G. M., \& Dores, A. (2018). Sistem Informasi Manajemen Marketing Tools Serta Penerapan Metode Ahp (Analytical Hierarchy Process) Pada Proses Uji Kualitas Barang (Studi Kasus : PT Edi Indonesia). Jurnal Cendikia, XVI, 107-114.

[5] Ahmad, R. F., \& Hasti, N. (2018). Sistem Informasi Penjualan Sandal Berbasis Web. Jurnal Teknologi dan Informasi, 8(1), 67-72. https://doi.org/10.34010/jati.v8i1.911

[6] Ferdiansyah Setya Pradana. (2019). Analisa Dan Perancangan Sistem Informasi Praktek Kerja Industri Menggunakan AHP. JUST IT : Jurnal Sistem Informasi, Teknologi Informatika dan Komputer, 10, 72 77.

[7] Firmansyah, B., \& Wihandar, A. M. (2020). Sistem Pendukung Keputusan Monitoring \& Evaluasi Kinerja Dosen Program Studi Informatika Fakultas Ilmu Komputer Ibi Kosgoro 1957 Menggunakan Metode Analythic Hierarchy Process ( AHP ). 1(2), 127-142.

[8] Ilhamizar, M. A., Ridwan, A. Y., Deni, M., \& Math, M. (2018). Perancangan Sistem Monitoring Kinerja Distribusi Produk Beras Menggunakan Metode SCOR Dan AHP Pada BULOG SubDivre Bandung. e-Proceeding of Engineering, 5(3), 6904.Maulana, A., Kurniawan, A., Keumala, W., Sukma, V. R., \& Saifudin, A. (2020). Pengujian Black Box pada Aplikasi Penjualan Berbasis Web Menggunakan Metode Equivalents Partitions (Studi Kasus: PT Arap Store). Jurnal Teknologi Sistem Informasi dan Aplikasi, 3(1), 50. https://doi.org/10.32493/jtsi.v3i1.4307

[9] Permana, R. A., Ridwan, A. Y., Yulianti, F., \& Si, S. (2019). Perancangan Sistem Monitoring Ketahanan Pangan Dan Mitigasi Bulog Subdivre Bandung. 6(2), 7137-7145.

[10] Ramanda, K. (2017). Sistem Informasi Manajemen Proyek Berbasis Web. Ijns.org, 6(4), 14-17.

[11] Robby Rachmatullah, D. (2016). Sistem Pendukung Keputusan Monitoring Mahasiswa Menggunakan Metode AHP dan Promethee. Speed, 8(Sistem Pendukung), 1-9.

[12] Siahaan, J. A. Y., Ridwan, A. Y., \& Akbar, M. D. (2019). Pengembangan Sistem Monitoring Indikator Kinerja Sustainable Distribution Berbasis Model Scor Pada Industri Penyamakan Kulit. eProceedings of Engineering, 5(3), 6750-6757. 